\title{
AN IMPROVED MODEL OF SOIL RESPONSE TO LOAD, UNLOAD AND RE-LOAD CYCLES IN AN OEDOMETER
}

\author{
ROY BUTTERFIELD ${ }^{\mathrm{i})}$
}

\begin{abstract}
There are a number of advantages to be gained by representing the oedometric compression of a soil skeleton, during virgin loading, unloading and subsequent reloading by ' $\log (v)$ versus $\log \left(p^{\prime}\right)$ ' relationships rather than the conventional ' $e$ versus $\log _{10}\left(p^{\prime}\right)$ ' expression. The paper presents an augmented version of the basic, two parameter $\left(C_{\mathrm{c}}^{\prime}\right.$, $\left.C_{\mathrm{s}}^{\prime}\right)$, ' $\log (v)$ versus $\log \left(p^{\prime}\right)$ ' model in which the addition of two further parameters $\left(C_{\mathrm{r}}^{\prime}, C_{\mathrm{o}}^{\prime}\right)$ enables a complete, nonlinear response for any load-unload-reload cycle to be reproduced. All four parameters, deduced from a single such cycle in an oedometer, can then be used to predict the response of the sample in any other unload-reload cycles. Results are presented from tests of this kind on a range of fine-grained soils to demonstrate the key attributes of the model. These include the generation of ' $\log \left(m_{\mathrm{v}}\right)$ versus $\log \left(p^{\prime}\right)$ ' diagrams that furnish practically useful $m_{\mathrm{v}}$ values applicable throughout any unload-reload cycle. The model also provides a simple means of assessing the overconsolidation ratio of an undisturbed soil sample.
\end{abstract}

Key words: compressibility, compression, consolidation test, constitutive equations of soil, OCR, overconsolidation, stress-strain curve (IGC: D5)

\section{INTRODUCTION}

In this paper $v=1+e$ is specific volume, and, following historical practice in relation to oedometer tests, $p^{\prime}$ is used to represent the vertical compressive effective stress in such a test. In a previous paper Butterfield (1979) pointed out that not only is the linearity of a $\log (v)$ versus $\log \left(p^{\prime}\right)$ diagram better than that of the traditional $e$ versus $\log _{10}\left(p^{\prime}\right)$ one, for both virgin loading and subsequent unloading of compressible soils, but also that it has other advantages, amongst which are: a gradient that generates natural strains directly and is therefore applicable to large strain deformation; a clarification of the important influence of the unloading stress ratio on reloading response and compression parameter values that are independent of the base of the logarithms used for plotting.

Adopting ' $\log (v)$ versus $\log \left(p^{\prime}\right)$ ' in lieu of ' $e$ versus $\log \left(p^{\prime}\right)$ ' as the basic compression model for fine-grained soils is very much more than a mere change of axis labelling. This paper shows how it can;

a. generate loading, unloading, reloading cycles in an oedometer, including not only a complete reloading loop such as that sketched in Fig. 1(a), but also intermediate unloading and reloading events, as exemplified by path E3 in Fig. 5(a).

b. reproduce the initial reloading curve subsequent to unloading a structurally intact sample and bringing it to equilibrium at a low stress level in an oedometer, as exemplified by path E1 in Fig. 4(a).

c. provide simple, practically useful expressions relating both $v$ and $m_{\mathrm{v}}$ to $p^{\prime}$ throughout all the above processes.

d. codify the major effect of the unloading ratio in the oedometer (i.e., the ratio of the virgin-curve $p_{\mathrm{a}}^{\prime}$ value to the unloaded $p_{\mathrm{b}}^{\prime}$ value, in Fig. 1(a)) on the form of reloading curves.

e. provide a rational prediction of the reloading curve (and thereby the $m_{\mathrm{v}}$ values), of an overconsolidated soil undergoing in-situ reloading back onto the virgin curve.

Although a hyperbolic relationship between compressibility and mean effective stress, as in Eq. (3), was proposed for clays, by Jaurez-Badillo (1965) the extension of the model to encompass all of virgin loading, unloading and reloading along a curved path is new. Den Haan (1992) published a generalised power law for virgin compression, which reduces to Eq. (2) as a special case, and demonstrated that it fitted experimental data better than ' $e-\log \left(p^{\prime}\right)$. Hashiguchi (1995) advocated using a $' \ln (v)-\ln \left(p^{\prime}\right)$ isotropic compression relationship in elastoplastic constitutive equations for soil; a topic that he appears to have been developing since 1974. For sands, where strains are relatively small, more general expressions have been suggested (Janbu, 1963; McDermott, 1972). The model presented here is a revised and substantially extended version of that published by Butterfield and Baligh (1996).

i) Professor Emeritus, Civil Engineering, University of Southampton, UK (rb@soton.ac.uk).

The manuscript for this paper was received for review on October 14, 2008; approved on December 16, 2010.

Written discussions on this paper should be submitted before November 1, 2011 to the Japanese Geotechnical Society, 4-38-2, Sengoku, Bunkyo-ku, Tokyo 112-0011, Japan. Upon request the closing date may be extended one month. 


\section{FORMULATION OF THE MODEL}

The central hypothesis is that the traditional ' $e$ versus $\log _{10}\left(p^{\prime}\right)$ expression,

$$
\begin{aligned}
& \left(e-e_{0}\right)=-C \log _{10}\left(p^{\prime} / p^{\prime}{ }_{0}\right) \quad \text { or } \\
& d e=-C(.435)\left(d p^{\prime} / p^{\prime}\right)
\end{aligned}
$$

in which, $\left(p_{0}^{\prime}, e_{0}\right)$ is a reference state and $C$ may be either the virgin compression index $C_{\mathrm{c}}$ or the swelling/recompression index $C_{\mathrm{s}}$, provides a less satisfactory basis for modelling soil compression in an oedometer than the relationship,

$$
\begin{aligned}
& \log \left(v / v_{0}\right)=-C^{\prime} \log \left(p^{\prime} / p_{0}^{\prime}\right) \quad \text { or } \\
& d v / v=-C^{\prime} d p^{\prime} / p^{\prime}
\end{aligned}
$$

which, incidentally, has the same form as an ideal adiabatic compression process.

The reference state is $\left(p_{0}^{\prime}, v_{0}\right)$ on the virgin compression curve and $C^{\prime}$ may be any one of $\left(C_{\mathrm{c}}^{\prime}, C_{\mathrm{s}}^{\prime}, C_{\mathrm{o}}^{\prime}, C_{\mathrm{r}}^{\prime}\right)$ as defined below. The sign convention used throughout is consistent with an increase in compressive stress reducing the magnitude of either $e$ or $v$. The $C^{\prime}$ parameters all represent slopes of lines resulting from a loading/unloading/reloading cycle in a typical oedometer-test plotted on $\log (v)-\log \left(p^{\prime}\right)$ axes as shown in Fig. 1(a). Although base-10 logarithms are used in figures throughout the paper this is done only for convenience in plotting; contrary to $\left(C_{\mathrm{c}}, C_{\mathrm{s}}\right)$, the $C^{\prime}$ values do not depend upon $\log \left(p^{\prime}\right)$ being expressed as $\log _{10}\left(p^{\prime}\right)$.

Specifically, as indicated diagramatically in Fig. 1(a),

a. $C_{\mathrm{c}}^{\prime}$ is the slope of the virgin compression line, located by $\left(p_{0}^{\prime}, v_{0}\right)$.

b. $C_{\mathrm{s}}^{\prime}$ is the slope of an unloading line from any point $\left(p_{\mathrm{a}}^{\prime}, v_{\mathrm{a}}\right)$ on $C_{\mathrm{c}}^{\prime}$.

c. $C_{\mathrm{r}}^{\prime}$ is the initial slope of the reloading curve from any point $\left(p_{\mathrm{b}}^{\prime}, v_{\mathrm{b}}\right)$ on a $C_{\mathrm{s}}^{\prime}$ unloading line.

d. $C_{\mathrm{o}}^{\prime}$ is the slope of the reloading curve where it intersects the $p^{\prime}=p_{\mathrm{a}}^{\prime}$ abscissa.

e. A reloading curve continues until it merges with the

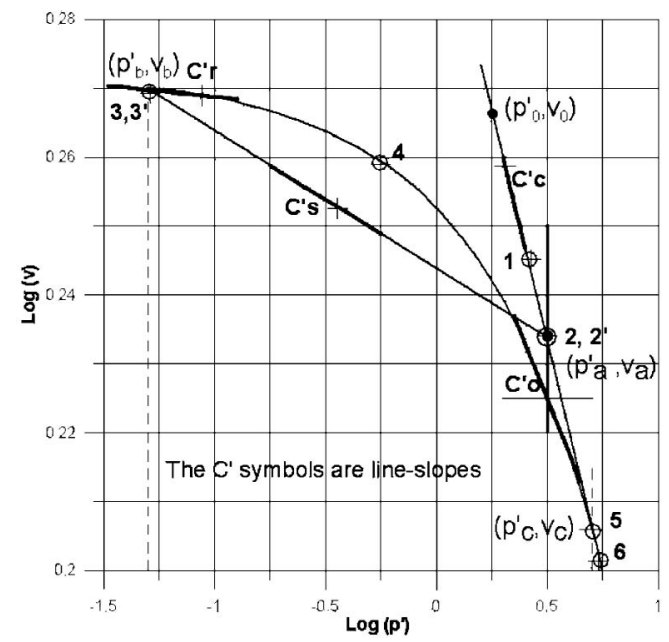

Fig. 1(a). Definition of $C^{\prime}$ compression symbols in a log $(v)$ versus $\log$ $\left(p^{\prime}\right)$ plot virgin curve at $\left(p_{\mathrm{c}}^{\prime}, v_{\mathrm{c}}\right)$.

In an oedometer $d v / v$ is identical to $d h / h$, where $h$ is the current height of the test sample. It would therefore be formally correct to associate $d v / v$ (a volumetric strain) solely with a spherical effective stress component and $d h / h$ with the co-linear vertical effective stress $\sigma_{\mathrm{v}}^{\prime}$. Consequently, when ' $\log (v)$ versus $\log \left(p^{\prime}\right)$ ' is referred to in this paper (by analogy with ' $e$ versus $\log \left(p^{\prime}\right)$ ), with $p^{\prime}$ representing the vertical effective stress in an oedometer in the traditional way, it is strictly representing a ' $\log (h)$ versus $\log \left(\sigma_{\mathrm{v}}^{\prime}\right)$ ' relationship in confined compresssion.

Since $d h / h$ is a natural strain it becomes convenient to redefine $m_{\mathrm{v}}$, the so-called 'coefficient of volume compressibility', also in terms of natural strain, as $\left(m_{\mathrm{v}} \cdot d p^{\prime}\right)=$ $-(d h / h)$. Hence, using Eq. (2),

$$
m_{\mathrm{v}} \cdot p^{\prime}=\mathrm{C}^{\prime} \quad \text { or } \quad \log \left(m_{\mathrm{v}}\right)=-\log \left(p^{\prime}\right)+\log \left(C^{\prime}\right)
$$

The second expression above is a linear equation, with gradient $=-1$, which, when plotted on $\left(\log \left(m_{\mathrm{v}}\right), \log \right.$ $\left.\left(p^{\prime}\right)\right)$ axes, intersects the $\log \left(p^{\prime}\right)=0$ abscissa at the value of $\log \left(C^{\prime}\right)$. Figure 1(b) typifies such a diagram on which the four, parallel $C^{\prime}$ lines relevant to Fig. 1(a) are shown.

The new definition of $m_{\mathrm{v}}$ is clearly equivalent to the conventional one when $h$ is sensibly constant $=h_{0}$, say. It is easily shown that the ' $\log (v)$ versus $\log \left(p^{\prime}\right)$ ' and the ' $e$ versus $\log \left(p^{\prime}\right)^{\prime}$ models then become identical with $C_{\mathrm{c}} /$ $\left(1+e_{0}\right)=C_{\mathrm{c}}^{\prime} /(.4343)$. If, in addition, $d p^{\prime}$ were small enough for $p^{\prime}$ also to remain essentially constant $=p_{0}^{\prime}$, say, then the model becomes locally linear with $d \varepsilon=$ $\left(d h / h_{0}\right)=\left(C_{\mathrm{c}}^{\prime} / p_{0}^{\prime}\right) d p^{\prime}$ (Butterfield, 1979).

The loading, unloading and reloading-cycle points (1, 2, 2', 3, 3', 4, 5, 6) in Fig. 1(a) map onto Fig. 1(b) as follows.

a. Path $(1,2)$ is virgin loading which tracks the lines labelled $C_{\mathrm{c}}^{\prime}$ in both figures along which, from Eq. (3), $m_{\mathrm{v}}=C_{\mathrm{c}}^{\prime} / p^{\prime}$.

b. Unloading starts at 2 in both figures. In Fig. 1(a), although points $2,2^{\prime}$ are coincident, there is a step change in the gradient as the relevant $C_{\mathrm{s}}^{\prime}$ line is joined. In Fig. 1(b) the jump in $m_{\mathrm{v}}$ value is reflected in the 2 to

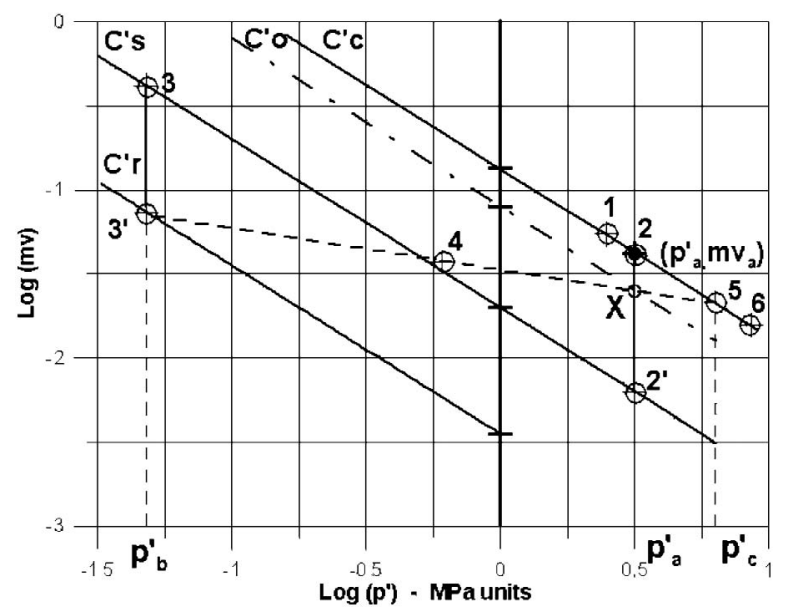

Fig. 1(b). Mapping of $\log (v)-\log \left(p^{\prime}\right) C^{\prime}$ lines in the $\log \left(m_{v}\right)$ versus $\log \left(p^{\prime}\right)$ plane 
$2^{\prime}$ step from the line labelled $C_{\mathrm{c}}^{\prime}$ onto that labelled $C_{\mathrm{s}}^{\prime}$.

c. The unloading path $\left(2^{\prime}, 3\right)$ in both diagrams tracks the lines labelled $C_{\mathrm{s}}^{\prime}$, along which, from Eq. (3), $m_{\mathrm{v}}=C_{\mathrm{s}}^{\prime} /$ $p^{\prime}$.

d. Reloading starts at 3 in both figures. In Fig. 1(a) points $3,3^{\prime}$ are coincident, although there is again a step change in the gradient as the reloading curve $\left(3^{\prime}\right.$, $4,5)$ is joined. In Fig. 1(b) the jump in $m_{\mathrm{v}}$ value is reflected in the 3 to $3^{\prime}$ step from the line labelled $C_{\mathrm{s}}^{\prime}$ onto that labelled $C_{\mathrm{r}}^{\prime}$.

e. The reloading curve in Fig. 1(a) then follows the path $(3,4,5)$ where it merges with the virgin line, proceeding along it to point 6 . In Fig. 1(b) point $3^{\prime}$ is on the $C_{\mathrm{r}}^{\prime}$ labelled line and $(5,6)$ are again on the $C_{\mathrm{c}}^{\prime}$ line, the path having passed through points 4 and $\mathrm{X}$.

f. A further, new and crucial assumption embedded in the model is that the reloading path $\left(3^{\prime}, 4, \mathrm{X}, 5\right)$, following unloading from a point on the virgin compression line, maps as a straight line, dashed in Fig. 1(b).

g. $\mathrm{X}$ is defined as the point at which the above line intersects the $p_{\mathrm{a}}^{\prime}$ abscissa. This point locates the chain-dotted line' labelled $C_{\mathrm{o}}^{\prime}$ in Fig. 1(b), which, in this case, establishes an approximate value for $\log \left(C_{\mathrm{o}}^{\prime}\right)=-1.1$, $C_{\mathrm{o}}^{\prime} \sim 0.08$, whence, from Eq. (3), $m_{\mathrm{v}}=C_{\mathrm{o}}^{\prime} / p^{\prime}$ a at X.

It is clear from Fig. 1(b) that $m_{\mathrm{v}}$ varies significantly throughout a loading regime such as the one described above and that its value is well defined in the model.

The slope of a reload line in a $\log \left(m_{\mathrm{v}}\right)-\log \left(p^{\prime}\right)$ diagram can be designated by $\theta$, with $\alpha=\tan (\theta)$, as in Fig. $1(\mathrm{c})$. The figure shows possible reload paths $\theta=\left(45^{\circ}, 0^{\circ}\right.$, $\left.-30^{\circ}\right)$, all of which, for a load cycle starting from $p_{\mathrm{a}}^{\prime}$, are predicted to pass through point $\mathrm{X}$. Consequently, during reloading $m_{\mathrm{v}}$ will decrease along paths with negative $\theta$ values, increase when $\theta$ is positive and only remain constant when $\theta$ is zero.

A key element in the justification of the model is therefore to establish that experimental data from sets of reloading curves do lie on $\left(3^{\prime}, 4, \mathrm{X}, 5\right)$ lines as required in

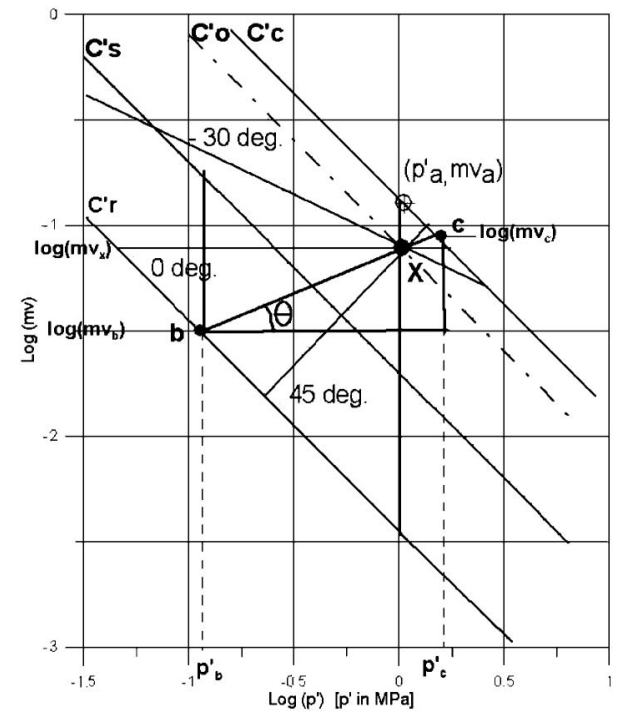

Fig. 1(c). Linear reload paths in the $\log \left(m_{v}\right)$ versus $\log \left(p^{\prime}\right)$ plane (f) and (g) above, or, conversely, that equations deduced from this assumption generate relationships that can reproduce real $\log (v)$ versus $\log \left(p^{\prime}\right)$ data along loading, unloading and reloading curves together with compatible values of $m_{\mathrm{v}}$.

\section{RELATIONSHIPS BETWEEN VARIABLES IN THE MODEL}

The Slope $\alpha$ of Reloading Lines Passing Through $X$ in a $\log \left(m_{v}\right)-\log \left(p^{\prime}\right)$ Diagram

The gradient $\alpha=\tan (\theta)$ of the reloading line (bc) in Fig. 1(c) is easily shown to be,

$$
\alpha=\log \left(m v_{\mathrm{c}} / m v_{\mathrm{b}}\right) / \log \left(p_{\mathrm{c}}^{\prime} / p_{\mathrm{b}}^{\prime}\right)
$$

Since $m_{\mathrm{v}}=C^{\prime} / p^{\prime}$ for any point on any $C^{\prime}$ line, it follows that

$$
\alpha=\log \left[\left(C_{\mathrm{c}}^{\prime} / p_{\mathrm{c}}^{\prime}\right) /\left(C_{\mathrm{r}}^{\prime} / p_{\mathrm{b}}^{\prime}\right)\right] / \log \left(p_{\mathrm{c}}^{\prime} / p_{\mathrm{b}}^{\prime}\right)
$$

whence

$$
(\alpha+1)=\log \left(C_{\mathrm{c}}^{\prime} / C_{\mathrm{r}}^{\prime}\right) / \log \left(p_{\mathrm{c}}^{\prime} / p_{\mathrm{b}}^{\prime}\right)
$$

or

$$
\left(p_{\mathrm{c}}^{\prime} / p_{\mathrm{b}}^{\prime}\right)=\left(C_{\mathrm{c}}^{\prime} / C_{\mathrm{r}}^{\prime}\right)^{\beta} \quad \text { where } \beta=1 /(\alpha+1)
$$

alternatively,

$$
\alpha=\log \left(m v_{\mathrm{x}} / m v_{\mathrm{b}}\right) / \log \left(p_{\mathrm{a}}^{\prime} / p_{\mathrm{b}}^{\prime}\right)
$$

whence

$$
(\alpha+1)=\log \left(C_{0}^{\prime} / C_{\mathrm{r}}^{\prime}\right) / \log \left(p_{\mathrm{a}}^{\prime} / p_{\mathrm{b}}^{\prime}\right)
$$

or

$$
\left(p_{\mathrm{a}}^{\prime} / p_{\mathrm{b}}^{\prime}\right)=\left(C_{0}^{\prime} / C_{\mathrm{r}}^{\prime}\right)^{\beta}
$$

Equating Eqs. (5a) and (6a) establishes the identity,

$$
\begin{aligned}
(\alpha+1) & =\log \left(C_{0}^{\prime} / C_{\mathrm{r}}^{\prime}\right) / \log \left(p_{\mathrm{a}}^{\prime} / p_{\mathrm{b}}^{\prime}\right) \\
& =\log \left(C_{\mathrm{c}}^{\prime} / C_{\mathrm{r}}^{\prime}\right) / \log \left(p_{\mathrm{c}}^{\prime} / p_{\mathrm{b}}^{\prime}\right)
\end{aligned}
$$

which provides $p_{c}^{\prime}$, the stress at which the reloading curve merges with the virgin curve, from the set of $C^{\prime}$ values and the 'unloading ratio' $\left(p_{\mathrm{a}}^{\prime} / p_{\mathrm{b}}^{\prime}\right)$.

A further consequence of Eqs. (6) is that, for a specified value of $\left(C_{0}^{\prime} / C_{\mathrm{r}}^{\prime}\right)$, the unloading ratio $\left(p_{\mathrm{a}}^{\prime} / p_{\mathrm{b}}^{\prime}\right)$, uniquely determines the value of $\alpha$ on reloading as shown in Fig. 2(a).

For example, the reloading path will be geometrically similar to the one shown in this figure whenever the unloading ratio $=64$. A set of reload paths for unloading ratios of $(64,32,8,2)$ is shown in Fig. 2(b) together with the relevant $\alpha$ values for a typical Venetian clay.

The Values of $m_{v}$ and $v$ during Reloading along a Path Through $X$

Along a reloading line in a $\log \left(m_{\mathrm{v}}\right)-\log \left(p^{\prime}\right)$ diagram $\log \left(m v / m v_{\mathrm{b}}\right)=\alpha \log \left(p^{\prime} / p_{\mathrm{b}}^{\prime}\right)$. Since point $b$ is on the $C_{\mathrm{r}}^{\prime}$ line, $m v_{\mathrm{b}}=C_{\mathrm{r}}^{\prime} / p_{\mathrm{b}}^{\prime}$ and

$$
m_{\mathrm{v}}=\left(C_{\mathrm{r}}^{\prime} / p^{\prime}\right)\left(p^{\prime} / p_{\mathrm{b}}^{\prime}\right)^{(\alpha+1)}
$$

or, 


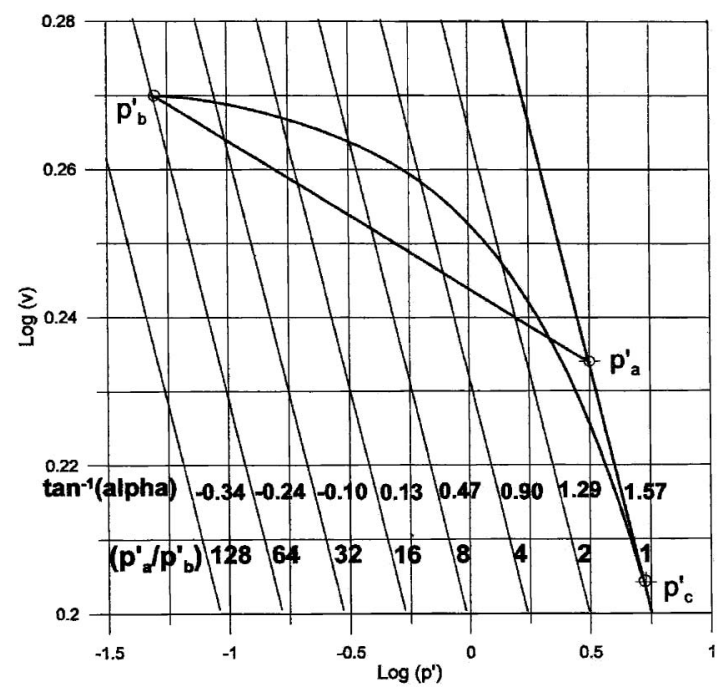

Fig. 2(a). Dependence of the slope $\theta=\tan ^{-1}(\alpha)$ of a reload path on unloading ratio

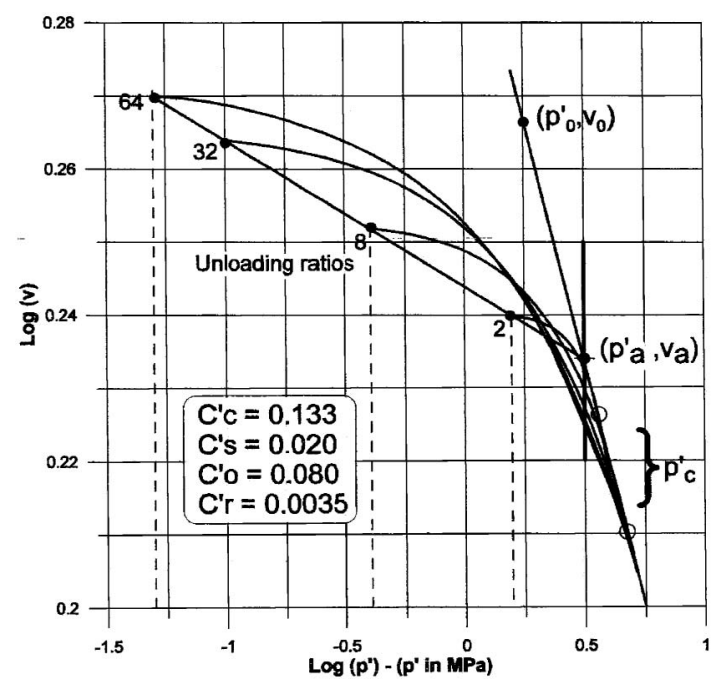

Fig. 2(b). Reloading curves for different unloading ratios along any $C_{\mathrm{s}}^{\prime}$ line

$$
\log \left(m_{\mathrm{v}}\right)=\alpha \log \left(p^{\prime}\right)+\log \left(C_{\mathrm{r}}^{\prime}\right)-(\alpha+1) \log \left(p_{\mathrm{b}}^{\prime}\right)
$$

Equation (8a) provides the value of $m_{\mathrm{v}}$ along a reloading curve as a modified version of the ubiquitous $m_{\mathrm{v}}=$ $\left(C^{\prime} / p^{\prime}\right)$ relationship that applies along any $C^{\prime}$ line. Equation (8b) has been used to plot the predicted ' $\log \left(m_{\mathrm{v}}\right)-$ $\log \left(p^{\prime}\right)^{\prime}$ reloading lines shown in Figs. 4(b), 7(b), 8(b), and $9(\mathrm{~b}):(\alpha+1)$ having already been fixed by the unloading ratio, via $\mathrm{Eq}$. (6a).

Replacing $m_{\mathrm{v}}$ in Eq. (8a) by its definition, $m_{\mathrm{v}}=$ $-d v /\left(d p^{\prime} . v\right)$ leads to,

$$
(d v / v)=-C_{\mathrm{r}}^{\prime}\left(p^{\prime}\right)^{\alpha} /\left(p_{\mathrm{b}}^{\prime}\right)^{(\alpha+1)} \cdot d p^{\prime}
$$

which can be integrated between limits $\left(p_{\mathrm{b}}^{\prime}, p^{\prime}\right)$ to provide an equation for $v$ along the reloading curve,

$$
\left(v / v_{\mathrm{b}}\right)=\operatorname{Exp}\left[\left(C_{\mathrm{r}}^{\prime} /(\alpha+1)\right)\left\{1-\left(p^{\prime} / p_{\mathrm{b}}^{\prime}\right)^{(\alpha+1)}\right\}\right]
$$

This equation has been used to plot the predicted ' $\log (v)$ $-\log \left(p^{\prime}\right)^{\prime}$ reloading curves in all the figures provided in the paper.

Optimising the Values of $C_{\mathrm{o}}^{\prime}, C_{\mathrm{r}}^{\prime}$ and $p_{\mathrm{c}}^{\prime}$

Because, in Fig. 1(c), point c lies on $C_{c}^{\prime}$, the slope of a predicted reloading curve at $p_{\mathrm{c}}^{\prime}$ in the $\log (v)-\log \left(p^{\prime}\right)$ diagram will always be $C_{\mathrm{c}}^{\prime}$. Nevertheless, the fact that $C_{\mathrm{c}}^{\prime}$, $C_{\mathrm{r}}^{\prime}$ and $p_{\mathrm{c}}^{\prime}$ are usually estimated from experimental data means that Eq. (7) will not be satisfied precisely by the various quantities involved. Consequently, the predicted reloading curve, although sloping correctly, may not merge with the virgin $C_{\mathrm{c}}^{\prime}$ line at $p_{\mathrm{c}}^{\prime}$ as it should. A simple iterative procedure that corrects an estimated value of $p_{\mathrm{c}}^{\prime}$, so that the set of parameters $\left(C_{\mathrm{c}}^{\prime}, C_{\mathrm{r}}^{\prime}, C_{\mathrm{o}}^{\prime}, p_{\mathrm{c}}^{\prime}\right)$ are consistent with $p_{\mathrm{a}}^{\prime}, p_{\mathrm{b}}^{\prime}$, and Eq. (7), is included in the Mathematica code provided in the APPENDIX. At this stage $C_{\mathrm{r}}^{\prime}$, which is less easy to evaluate from experimental data, may be adjusted and the code re-run (which simultaneously modifies $C_{\mathrm{o}}^{\prime}$ and $p_{\mathrm{c}}^{\prime}$ ) to optimise the overall fit of the model to the data. Once determined, the self-consistent set of $C^{\prime}$ values can be used to predict the complete nonlinear reloading response of the oedometer sample for any value of the initial unloading ratio.

The role of the $C_{\mathrm{s}}^{\prime}$ parameter is to provide, together with $C_{\mathrm{c}}^{\prime}$, values of $\left(v_{\mathrm{a}}, v_{\mathrm{b}}, v_{\mathrm{c}}\right)$ for specified values of ( $p_{0}^{\prime}$, $\left.v_{0}\right), p_{\mathrm{a}}^{\prime}, p_{\mathrm{b}}^{\prime}$ and $p_{\mathrm{c}}^{\prime}$. Since both $\left(p_{\mathrm{a}}^{\prime}, v_{\mathrm{a}}\right)$ and $\left(p_{0}^{\prime}, v_{0}\right)$ lie on the $C_{\mathrm{c}}^{\prime}$ line and $\left(p_{\mathrm{b}}^{\prime}, v_{\mathrm{b}}\right),\left(p_{\mathrm{a}}^{\prime}, v_{\mathrm{a}}\right)$ on a $C_{\mathrm{s}}^{\prime}$ line we have,

$$
\begin{aligned}
& \left(v_{\mathrm{a}} / v_{0}\right)=\left(p_{0}^{\prime} / p_{\mathrm{a}}^{\prime}\right)^{C_{\mathrm{c}}^{\prime}},\left(v_{\mathrm{b}} / v_{\mathrm{a}}\right)=\left(p_{\mathrm{a}}^{\prime} / p_{\mathrm{b}}^{\prime}\right)^{C_{\mathrm{s}}^{\prime}}, \\
& \left(v_{\mathrm{c}} / v_{0}\right)=\left(p_{0}^{\prime} / p_{\mathrm{c}}^{\prime}\right)^{C_{\mathrm{c}}^{\prime}}
\end{aligned}
$$

Reciprocally, if $\left(p_{\mathrm{b}}^{\prime}, v_{\mathrm{b}}\right)$ is known, typically after unloading a nominally-undisturbed soil sample, then the 'originating' $\left(p_{\mathrm{a}}^{\prime}, v_{\mathrm{a}}\right)$ point on the virgin $C_{\mathrm{c}}^{\prime}$ line, can be determined. Eliminating $v_{\mathrm{a}}$ between the first two expressions in Eqs. (10) establishes the value of $p_{\mathrm{a}}^{\prime}$,

$$
p_{\mathrm{a}}^{\prime\left(C_{\mathrm{c}}^{\prime}-C_{\mathrm{s}}^{\prime}\right)}=\left(v_{0} / v_{\mathrm{b}}\right) \cdot\left(p_{0}^{\prime C_{\mathrm{c}}^{\prime}} / p_{\mathrm{b}}^{\prime C_{s}^{\prime}}\right)
$$

Substituting $p_{\mathrm{a}}^{\prime}$ into the first of Eqs. (10) provides the value of $v_{\mathrm{a}}$.

A further point worth noting is that if the current insitu vertical stress is $p_{\mathrm{i}}^{\prime}$ at point $i$ in Fig. 3(a) and the $C_{\mathrm{s}}^{\prime}$ line through $i$ intersects the $C_{\mathrm{c}}^{\prime}$ line at $h$ then $p_{\mathrm{h}}^{\prime}$ will be the historic maximum value of $p^{\prime}$ and $\left(p_{\mathrm{h}}^{\prime} / p_{\mathrm{i}}^{\prime}\right)$ will provide a rational estimate of the overconsolidation ratio $(\eta)$ of the soil sample.

The in-situ reloading path from $p_{\mathrm{i}}^{\prime}$, that can be constructed from the $C^{\prime}$ parameters as explained previously, will start from this point and the associated ' $\log \left(m_{\mathrm{v}}\right)-$ $\log \left(p^{\prime}\right)$ line can be established from Eq. (8). These two processes are illustrated in Figs. 3(a) and 3(b) for $\eta=6$. In Fig. 3(a) the complete $\left(h, b, c_{1}\right)$ loading path represents the idealised response of a soil sampled, unloaded and reloaded in an oedometer and the path $\left(h, i, c_{2}\right)$ the predicted in-situ response of the soil. In Fig. 3(b), the sequences of points $\left(h^{\prime}, h^{\prime \prime}, b^{\prime}, b^{\prime \prime}, c_{1}^{\prime}\right)$ and $\left(h^{\prime}, h^{\prime \prime}, i^{\prime}, i^{\prime \prime}\right.$, $\left.c_{2}^{\prime}\right)$ illustrate how the value of $m_{\mathrm{v}}$ will change throughout the two reloading processes (decreasing along the first path but increasing along the second).

Very frequently the value of $\eta$ is likely to be only a little 


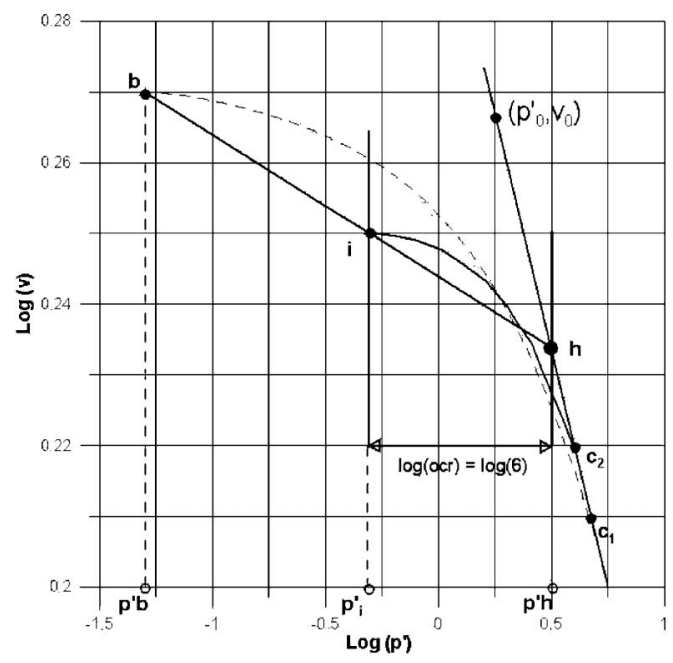

Fig. 3(a). An overconsolidated soil at point $h$, unloaded to point $b$ during sampling and to point $i$ in-situ; $O C R=6$. Reloading from $i$ will take it to point $c_{2}$

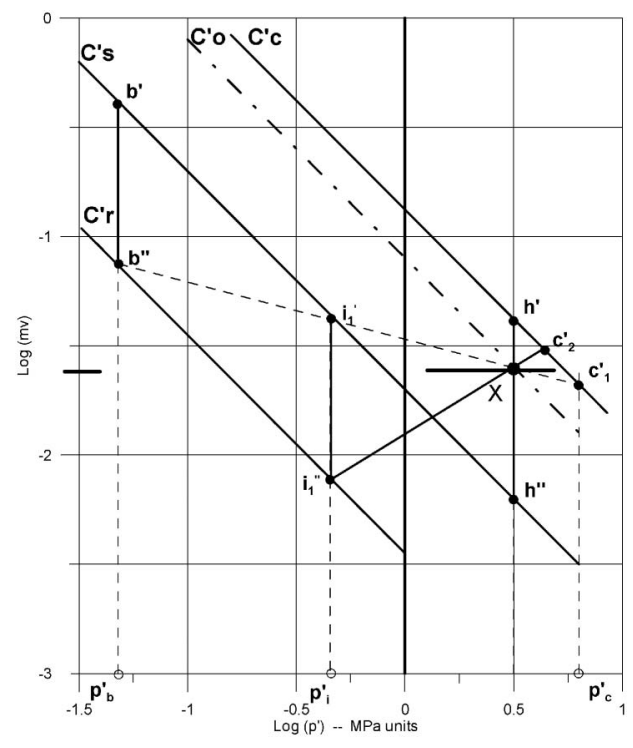

Fig. 3(b). The $\log \left(m_{\mathrm{v}}\right)$ versus $\log \left(p^{\prime}\right)$ diagram corresponding to Fig. 2(a)

greater than unity and $\theta$ will approach $90^{\circ}$ (Fig. 1(c)). In this case $m v_{\mathrm{a}}=m v_{\mathrm{h}}=C_{\mathrm{c}}^{\prime} / p_{\mathrm{h}}^{\prime}$ and $m v_{\mathrm{b}}=m v_{\mathrm{i}}=C_{\mathrm{r}}^{\prime} / p_{\mathrm{i}}^{\prime}$ with $p_{\mathrm{h}}^{\prime}$ $\approx p_{\mathrm{i}}^{\prime}$. The mean value of $m_{\mathrm{v}}=m_{\mathrm{v}}^{*}$, say, over the reload path is then $m_{\mathrm{v}}^{*}=\left(C_{\mathrm{c}}^{\prime}+C_{\mathrm{r}}^{\prime}\right) /\left(2 p_{\mathrm{i}}^{\prime}\right)$, which is slightly more than half of the value it would have for a normally consolidated soil with $\eta=1$. Were the reload ratio to be much less than $\eta$ it is clear from Fig. 3(b) that $m_{\mathrm{v}}^{*}<C_{\mathrm{s}}^{\prime} / p_{\mathrm{i}}^{\prime}$ is quite possible.

Such $m_{\mathrm{v}}^{*}$ values have been used (Butterfield et al., 2003) to calculate the subsidence of Venice due to drawdown in the underlying acquifers between 1938 and 1970. The resulting prediction, $146 \mathrm{~mm}$, was much closer to the one generally accepted of about $140 \mathrm{~mm}$-based on unusually good field data-(Ricceri and Butterfield, 1974; Butterfield, 2004), than Rowe's (1975) estimate of $205 \mathrm{~mm}$ derived from the same database and a conventional interpre- tation of the compressibility of the soil column.

Change in Thickness of a Laterally Confined Soil Layer If $h$ is the thickness of the layer, then for two states ( $p_{1}^{\prime}$, $\left.v_{1}\right),\left(p_{2}^{\prime}, v_{2}\right)$ on a load path traversing any $C^{\prime}$ line, from Eq. (2),

$$
\log \left(h_{2} / h_{1}\right)=-C^{\prime} \log \left(p_{2}^{\prime} / p_{1}^{\prime}\right)
$$

which provides the change in layer thickness $\left(h_{1}-h_{2}\right)$ for a change $\left(p_{2}^{\prime}-p_{1}^{\prime}\right)$ in effective vertical stress. If the two states lie on a curved reload line, located by $\left(p_{\mathrm{b}}^{\prime}, v_{\mathrm{b}}\right)$ and defined by $\alpha$, then Eq. (9) leads to,

$$
\left(h_{2} / h_{1}\right)=\operatorname{Exp}\left[\left(C_{\mathrm{r}}^{\prime} \cdot \beta\right)\left\{\left(p_{1}^{\prime} / p_{\mathrm{b}}^{\prime}\right)^{1 / \beta}-\left(p_{2}^{\prime} / p_{\mathrm{b}}^{\prime}\right)^{1 / \beta}\right\}\right]
$$

\section{ILLUSTRATIVE EXAMPLES COMPARING MODEL OUTPUT WITH OEDOMETER-TEST DATA}

The following five sets of Figs. $(4,5,7,8,9)$ illustrate typical results for natural clays from Boston-Cambridge, Venice, Modena, Bothkennar and a reconstituted Kaolin clay. They have been selected specifically to cover the same range of fine-grained soils (clays to the silt/sand borderline) to which the ' $e$ versus $\log \left(p^{\prime}\right)$ model is usually applied.

Figure 4(a) shows an oedometer-test, $\log (v)-\log \left(p^{\prime}\right)$ diagram (dashed lines) for a natural, Boston-Cambridge clay, $w_{\mathrm{L}}=40 \%, P I=18 \%$ (Lambe and Whitman, 1969) and the set of $C^{\prime}$ parameters that were used to generate the full lines which match the data extremely well. The values of $C_{\mathrm{c}}^{\prime}$ and $C_{\mathrm{s}}^{\prime}$ were scaled directly from the loadloop E1 data plot together with approximate values for $C_{\mathrm{r}}^{\prime}, C_{\mathrm{o}}^{\prime}$ and $p_{\mathrm{c}}^{\prime}$. The latter parameters were then adjusted iteratively, as explained in the APPENDIX, to obtain a complete set of self-consistent values enabling model predictions to be superimposed on the experimental data for all of the load-unload cycles shown in Fig. 4(a).

The predicted $\log \left(m_{\mathrm{v}}\right)$ versus $\log \left(p^{\prime}\right)$ relationship for the reloading section of loop E1, is shown (dashed) in Fig. 4(b). It suggests that that $m_{\mathrm{v}}$ will remain constant along it (i.e., $\alpha=$ zero) which is in good agreement with the less regular, superimposed (chain-dotted) line derived directly from the oedometer data. It follows from Eq. (6a) that the $\alpha=0$ condition is specific to an unloading ratio $\left(p_{\mathrm{a}}^{\prime} / p_{\mathrm{b}}^{\prime}\right)=\left(C_{\mathrm{o}}^{\prime} / C_{\mathrm{r}}^{\prime}\right)$. From Fig. $4(\mathrm{a})\left(p_{\mathrm{a}}^{\prime} / p_{\mathrm{b}}^{\prime}\right)=10$ in the oedometer test whereas, from the model, the value of $\left(C_{\mathrm{o}}^{\prime} / C_{\mathrm{r}}^{\prime}\right)=9.3$ for the Boston clay.

Loop E2 also has an unloading ratio $=10$, therefore $m_{\mathrm{v}}$ will again remain constant along the reloading section of this path. Although such unloading and reloading ratios are common in oedometer tests they are only likely to occur in practice at, for example, shallow depths under foundations.

The second example, Fig. 5, relates to a, nominally-undisturbed, silty-clay sample from the Venetian lagoon $\left(w_{\mathrm{L}}\right.$ $=34 \%, P I=14 \%$ )-Cola and Simonini (2002). As in the previous example, the $C^{\prime}$ parameters shown were derived from the E1 load cycle and used to interpret the remaining load/unload events (E2, E3). The measured data and 


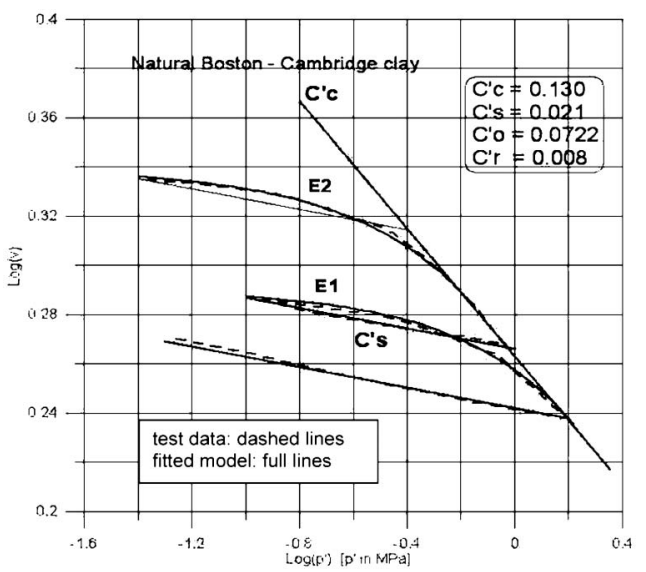

Fig. 4(a). Measured and predicted load, unload and reload paths for a natural Boston-Cambridge clay

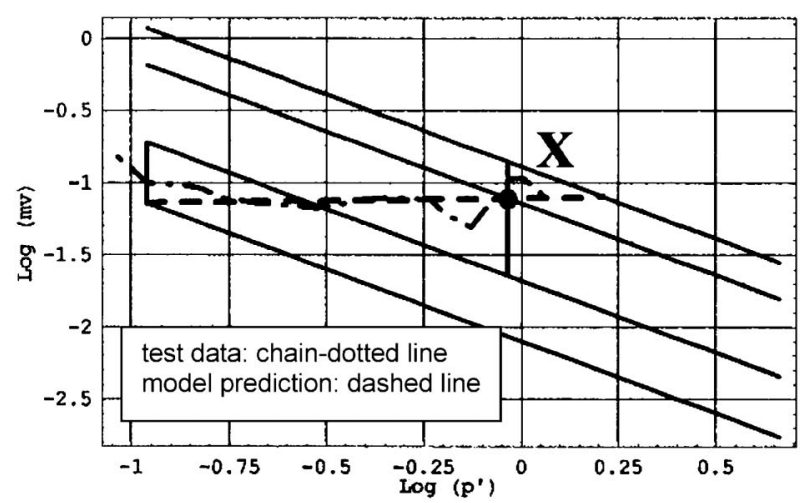

Fig. 4(b). The corresponding $\log \left(m_{\mathrm{v}}\right)$ verus $\log \left(p^{\prime}\right)$ diagram for the reloading path in $\mathbf{E} 1$

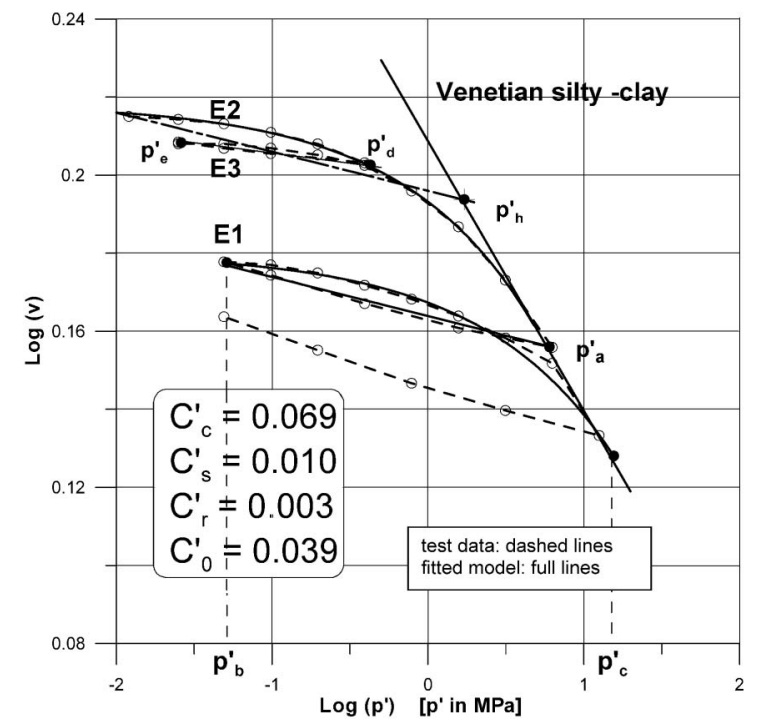

Fig. 5. Measured and predicted load, unload and reload paths for a natural Venetian silty-clay

the model predictions of it are virtually identical, including an intermediate unload-reload cycle at E3. How the latter can be modelled is explained below.

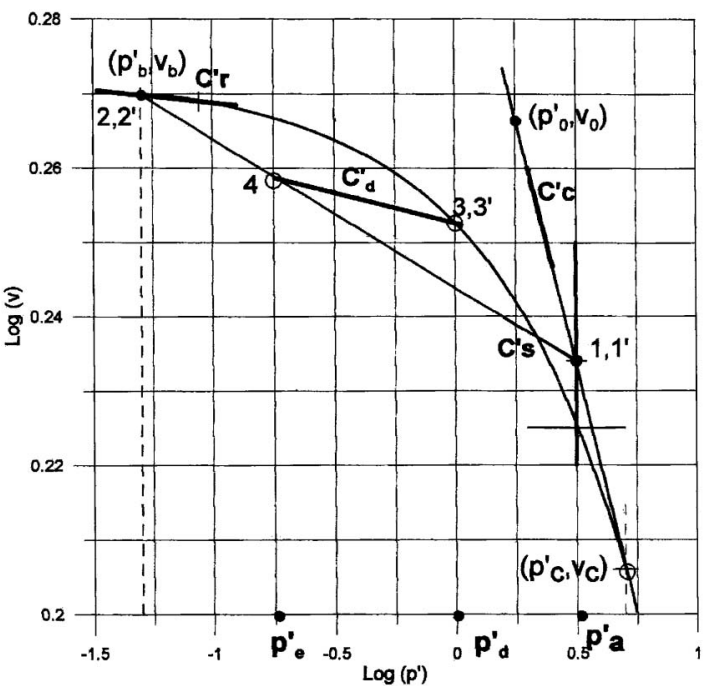

Fig. 6(a). Definition of an intermediate unload-reload path, slope $C_{\mathrm{d}}^{\prime}$

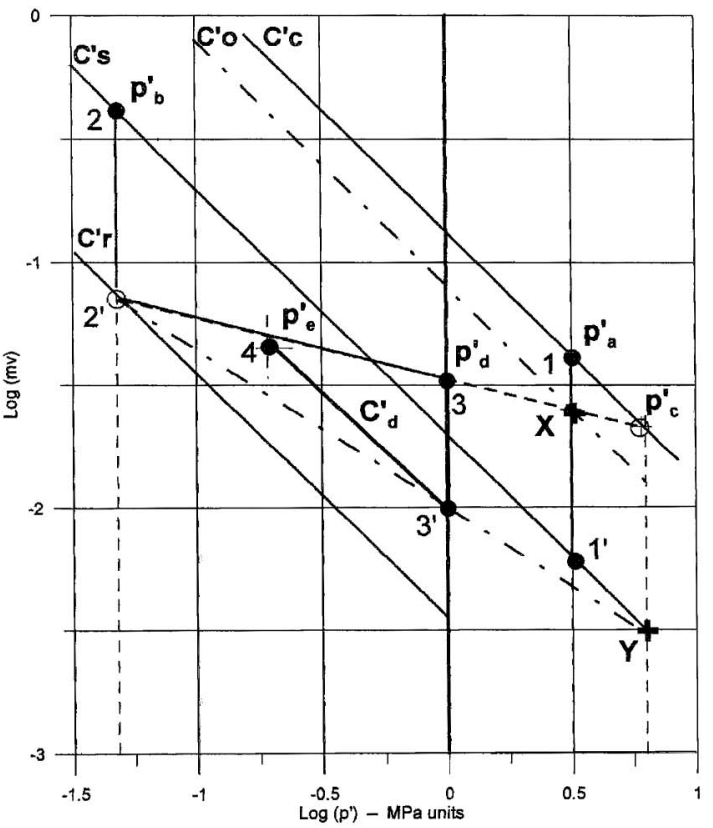

Fig. 6(b). The corresponding $\log \left(m_{\mathrm{v}}\right)$ versus $\log \left(p^{\prime}\right)$ diagram

\section{INTERMEDIATE UNLOAD - RELOAD CYCLES}

In Fig. 5 the zone marked E3 illustrates an intermediate load-unload cycle in which unloading starts from a point, $p^{\prime}=p_{\mathrm{d}}^{\prime}$, on a reloading curve rather than the virgin loading line, and continues to $p^{\prime}=p_{\mathrm{e}}^{\prime}$, providing evidence that, in a $\log (v)-\log \left(p^{\prime}\right)$ diagram,

a. such an intermediate unloading path is approximately a straight line.

b. the slope of the line, $C_{\mathrm{d}}^{\prime}$ say, is such that $C_{\mathrm{r}}^{\prime} \leq C_{\mathrm{d}}^{\prime} \leq C_{\mathrm{s}}^{\prime}$, since, were the unloading to start on the $C_{\mathrm{c}}^{\prime}$ line $C_{\mathrm{d}}^{\prime}=$ $C_{\mathrm{s}}^{\prime}$, whereas, if it started on the $C_{\mathrm{r}}^{\prime}$ line near the point $\left(p_{\mathrm{b}}^{\prime}, v_{\mathrm{b}}\right)$ then $C_{\mathrm{d}}^{\prime}=C_{\mathrm{r}}^{\prime}$.

c. the intermediate reloading path retraces the unloading line very closely.

In order to model this process one further assumption 
is made: that the value of $C_{\mathrm{d}}^{\prime}$ varies linearly with $\log \left(p^{\prime}\right)$, from $C_{\mathrm{s}}^{\prime}$ to $C_{\mathrm{r}}^{\prime}$, as $\log \left(p_{\mathrm{d}}^{\prime}\right)$, the starting point of the unloading process, moves from $p_{\mathrm{c}}^{\prime}$ to $p_{\mathrm{b}}^{\prime}$ in Fig. 6(a). This assumption leads to the following equation from which the value of $C_{\mathrm{d}}^{\prime}$ can be deduced.

$$
\log \left(C_{\mathrm{d}}^{\prime} / C_{\mathrm{r}}^{\prime}\right) / \log \left(C_{\mathrm{s}}^{\prime} / C_{\mathrm{r}}^{\prime}\right)=\log \left(p_{\mathrm{d}}^{\prime} / p_{\mathrm{b}}^{\prime}\right) / \log \left(p_{\mathrm{c}}^{\prime} / p_{\mathrm{b}}^{\prime}\right)
$$

The process is easy to follow graphically, as illustrated in Fig. 6(a), and the related $\log \left(m_{\mathrm{v}}\right)-\log \left(p^{\prime}\right)$ diagram Fig. $6(\mathrm{~b})$, in which the $\left(1,1^{\prime}, 2,2^{\prime}, 3\right)$ section is a standard unload/reload path. Intermediate unloading starts from 3 and, in Fig. 6(b), goes to $3^{\prime}$, a point on the line joining $2^{\prime}$ to $\mathrm{Y}$. ( $\mathrm{Y}$ is the point on $C_{\mathrm{s}}^{\prime}$ at which $p^{\prime}=p_{\mathrm{c}}^{\prime}$ ) Unloading proceeds from $3^{\prime}$ to 4 , along the $C_{\mathrm{d}}^{\prime}$ line, as defined in Eq. (15). Reloading retraces points $\left(4,3^{\prime}, 3\right)$ where it rejoins the $\left(2^{\prime}, X\right)$ path again and follows it to join the virgin compression line at $p_{\mathrm{c}}^{\prime}$. Along any $C_{\mathrm{d}}^{\prime}$ line, for both unloading and reloading, $m_{\mathrm{v}}=C_{\mathrm{d}}^{\prime} / p^{\prime}$. The line superimposed on the intermediate-cycle data in Fig. 6(a), which it interprets satisfactorily, was derived this way.

The third example, Figs. $7(a, b)$, relates to a, nominally-undisturbed, high-plasticity, clay sample from Modena, Lancellotta (2008), depth $14.5 \mathrm{~m}, w_{\mathrm{L}}=90 \%, P I$ $=55 \%$. The oedometer test reported had, intentionally, numerous unloading-reloading excursions each with substantially more loading stages on them than usual. The values of the $C^{\prime}$ parameters were fitted to a single loading loop (the penultimate one) and found to be $\left(C_{\mathrm{c}}^{\prime}=0.105\right.$, $\left.C_{\mathrm{s}}^{\prime}=0.028, C_{\mathrm{o}}^{\prime}=0.060, C_{\mathrm{r}}^{\prime}=0.011\right)$. The correspondence between the full lines with data points and the predicted curves in Fig. 7(a) is good. It is, however, evident in the figure that the $C_{s}^{\prime}$ lines become steeper as the specific volume from which unloading starts on $C_{\mathrm{c}}^{\prime}$ decreases (i.e., $C_{s}^{\prime}=$ constant is a less good approximation for this plastic clay at higher consolidation pressures). Such behaviour can be accommodated in the model by deducing a relationship between the measured values of $C_{s}^{\prime}$ and the initiating value of $v_{\mathrm{a}}$ for each of the five unloading paths explored in the test. The results shown in Fig. 7(a), including the final (dashed) unloading line, were achieved by fitting a polynomial to the unloading data. In this case,

$$
C_{\mathrm{s}}^{\prime \prime}=a_{0}+a_{1} \cdot v_{\mathrm{a}}+a_{2}\left(v_{\mathrm{a}}\right)^{2}
$$

with $a_{0}=-.0084, a_{1}=, 0831$ and $a_{2}=-.0359$, whereas all the previous figures simply use $a_{0}=C_{s}^{\prime}$ and $a_{1}=a_{2}=0$.

The benefit derived from more detailed reloading data is evident in Fig. 7(b) in which the coincidence between the predicted and measured values of $\log \left(m_{\mathrm{v}}\right)$ along the penultimate reloading stage is very good.

In this case $\alpha>0$, the unloading ratio $\approx 16$, and $m_{v}$ decreased slightly during reloading (see Fig. 2(a)).

The uppermost reloading curve in Fig. 7(a), and also those in Figs. 4(a), 5(a), 8(a) and 9, are for nominally-undisturbed samples on first reloading after installation in the oedometer. In principle, such curves should be members of the complete family of $\log (v)-\log \left(p^{\prime}\right)$ reloading curves for the soil. As explained previously, this assumption enables the in-situ overconsolidation ratio to be esti-

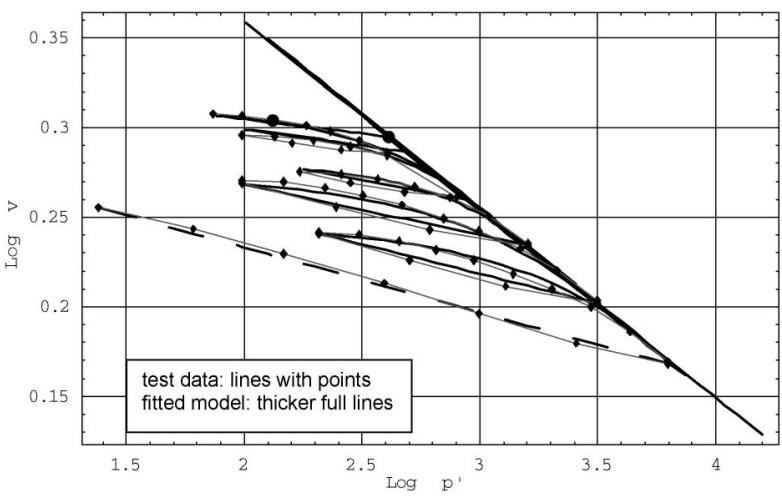

Fig. 7(a). Measured and predicted load, unload and reload paths for a natural Modena clay

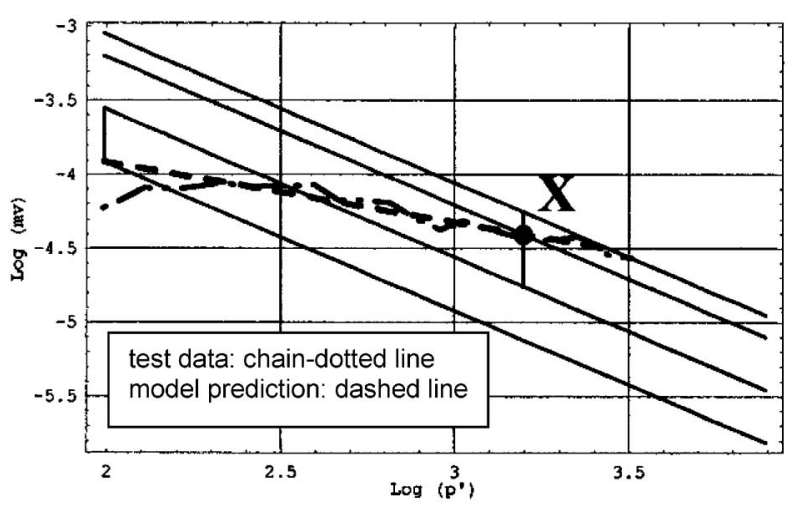

Fig. 7(b). The corresponding $\log \left(m_{\mathrm{v}}\right)$ versus $\log \left(p^{\prime}\right)$ diagram

mated. In Fig. 7(a) the two large points on this curve locate $\log \left(p_{\mathrm{h}}^{\prime}\right)$ and $\log \left(p_{\mathrm{i}}^{\prime}\right)$, logarithms of the estimated maximum past vertical effective stress and the current insitu value respectively, as $(2.6,2.1)$, with $p^{\prime}$ in $\mathrm{kPa}$. Hence $\log \eta=.5$ and $\eta \approx 3.2$.

Figures $8(\mathrm{a}, \mathrm{b})$ show conventional oedometer-test results for a reconstituted Kaolin $\left(w_{\mathrm{L}}=52 \%, P I=22 \%\right)$, (Baligh, 1984), whereas all other tests reported were on natural soils. This example, again presents unload-reload events with closely similar, but not identical, unload ratios $(\approx 4)$. In this case the dashed reload lines, shown for both load cycles in Fig. 8(b), are inclined at approximately $45^{\circ}$ (i.e., $\alpha \approx 1$ ) and the value of $m_{v}$ increases by a factor of about 4 along them.

The data points, at which $m_{\mathrm{v}}$ was assessed, are labelled correspondingly in both figures from which it is evident that the deviation between the data and the model predictions in Fig. 8(b) is substantial. The principal reason for this is because relatively few load points are recorded in conventional oedometer tests, therefore the values of $m_{\mathrm{v}}$ are derived from rather poorly defined gradients (it would therefore be preferable to calculate $m_{\mathrm{v}}$ from digitised smooth curves through the data points). The agreement between model and data is very much closer in the basic $\log \left(p^{\prime}\right)$ versus $\log (v)$ diagram, Fig. 8(a) and, overall, the model does provide a consistent interpretation of the manner in which $v$ and $m_{\mathrm{v}}$ vary throughout the loading 


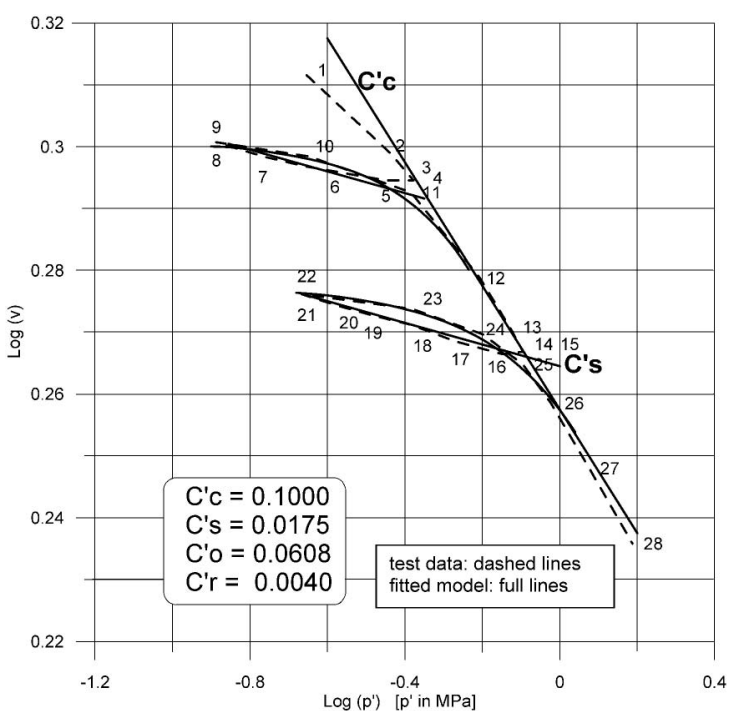

Fig. 8(a). Measured and predicted load, unload and reload paths for reconstituted Kaolin clay

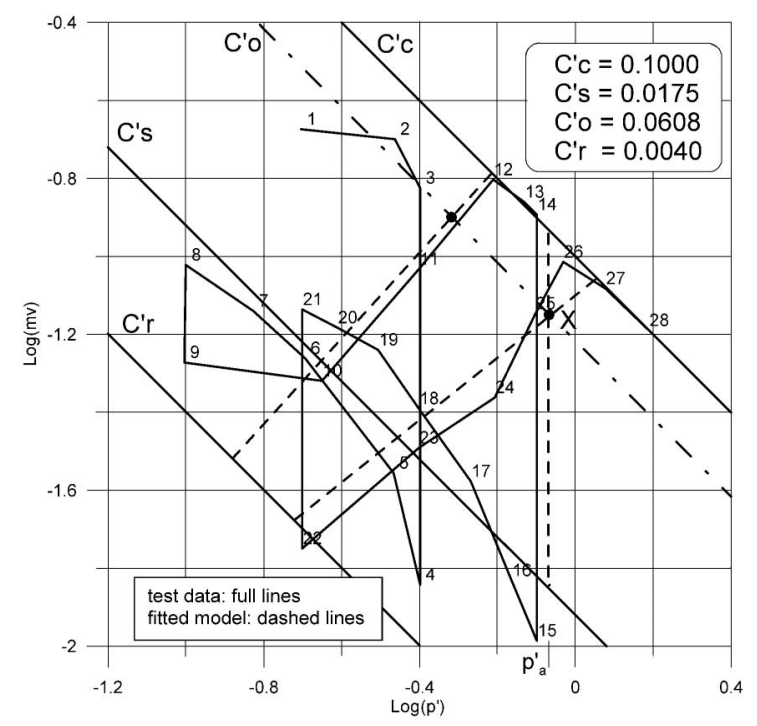

Fig. 8(b). The corresponding $\log \left(m_{v}\right)$ versus $\log \left(p^{\prime}\right)$ diagram

cycles.

Figure 9(a) shows reasonably good agreement between model prediction and experimental data for laterally-confined compression tests on Bothkennar normally consolidated silty-clay, Nash et al. (2006), demonstrating again the value of tests with numerous load increments. These results are of interest, (a) because they were obtained from cycled triaxial $K_{0}$ tests simulating confined compression and (b) they are unusual in that they cover a range of unloading ratios (from 3 to 18$)$. The $C^{\prime}$ values $\left(C_{\mathrm{c}}^{\prime}=\right.$ $\left.0.160, C_{\mathrm{s}}^{\prime}=0.021, C_{\mathrm{o}}^{\prime}=0.086, C_{\mathrm{r}}^{\prime}=0.007\right)$, derived from the penultimate loading cycle, were used to predict the experimental results shown for the other three cycles.

Because the sample was always unloaded to the same $p^{\prime}$ value $m_{\mathrm{v}}$ will vary quite differently during each reloading phase. Figure 9(b) shows both the predicted values of $m_{\mathrm{v}}$ along the 4 reloading paths (dashed lines), each with its

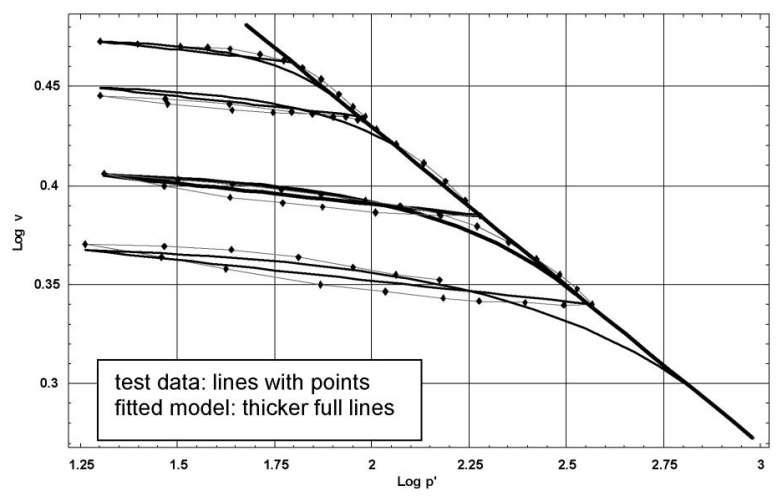

Fig. 9(a). Measured and predicted load, unload and reload paths for natural Bothkennar silty-clay in a cycle of $K_{0}$ tests (BN7)

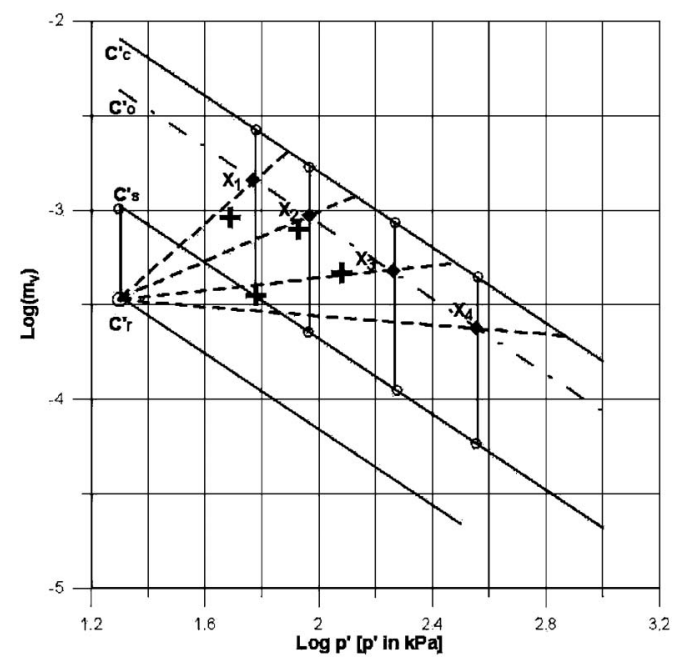

Fig. 9(b). Range of $m_{\mathrm{v}}$ values along four reload paths unloaded to identical values of $p^{\prime}$, Bothkennar silty-clay tests (BN7)

own ' $\mathrm{X}$ ' point, and the mean $\left(\log p^{\prime}, \log m_{\mathrm{v}}\right)$ points, calculated from the BN7 test data (bold crosses), which lie quite close to their predicted positions.

\section{SUMMARY OF PARAMETER VALUES}

Table 1 contains descriptions, classification information and $C^{\prime}$ values covering a range of soils, from which, for the natural silty-clays, $C_{\mathrm{o}}^{\prime} \approx 0.6 C_{\mathrm{c}}^{\prime}$ and $C_{\mathrm{r}}^{\prime} \approx 0.3 C_{\mathrm{s}}^{\prime}$.

\section{CONCLUDING REMARKS}

It has been demonstrated that, by plotting oedometer test data in the form ' $\log (v)$ versus $\log \left(p^{\prime}\right)$ ' and describing the slopes of the resulting set of load, unload and reload curves by four readily determined parameters $\left(C_{\mathrm{c}}^{\prime}\right.$, $C_{\mathrm{s}}^{\prime}, C_{\mathrm{o}}^{\prime}, C_{\mathrm{r}}^{\prime}$ ), the response of a range of clay and silty-clay soils (i.e., those conventionally interpreted by an ' $e$ versus $\log _{10}\left(p^{\prime}\right)$ ' relationship) to any other oedometric loadpath can be predicted very satisfactorily. The addition of two parameters $\left(C_{\mathrm{o}}^{\prime}, C_{\mathrm{r}}^{\prime}\right)$ to the author's previous $\left(C_{\mathrm{c}}^{\prime}, C_{\mathrm{s}}^{\prime}\right)$ model, that interpreted loading along, and unloading 
Table 1. $C^{\prime}$ values for various soils

\begin{tabular}{|c|c|c|c|c|c|c|c|c|c|}
\hline & $C_{\mathrm{c}}^{\prime}$ & $C_{s}^{\prime}$ & $C_{\mathrm{s}}^{\prime} / C_{\mathrm{c}}^{\prime}$ & $C_{\mathrm{o}}^{\prime}$ & $C_{\mathrm{o}}^{\prime} / C_{\mathrm{c}}^{\prime}$ & $C_{\mathrm{r}}^{\prime}$ & $C_{\mathrm{r}}^{\prime} / C_{\mathrm{s}}^{\prime}$ & $w_{\mathrm{L}} \%$ & $P I \%$ \\
\hline Boston-Camb.clay@23 m & 0.130 & 0.021 & 0.162 & 0.072 & 0.554 & 0.008 & 0.38 & 40 & 18 \\
\hline Bothkennar silty-clay BN7 & 0.160 & 0.021 & 0.175 & 0.086 & 0.538 & 0.007 & 0.33 & $\sim 77$ & $\sim 44$ \\
\hline Reconstituted Kaolin & 0.100 & 0.018 & 0.180 & 0.061 & 0.61 & 0.004 & 0.22 & 52 & 22 \\
\hline S Stefano silty clay@6.3 m & 0.124 & 0.018 & 0.145 & 0.070 & 0.564 & 0.004 & 0.22 & 45 & 16 \\
\hline Venetian silty clay@2m & 0.069 & 0.010 & 0.145 & 0.039 & 0.558 & 0.003 & 0.30 & 34 & 14 \\
\hline Venetian silty clay@18m & 0.063 & 0.011 & 0.175 & 0.036 & 0.571 & 0.004 & 0.36 & 34 & 14 \\
\hline Venetian clay@ 0 m & 0.133 & 0.020 & 0.154 & 0.080 & 0.602 & 0.004 & 0.20 & 62 & 28 \\
\hline Pisa clay@13.4m & 0.169 & 0.029 & 0.172 & 0.098 & 0.580 & 0.010 & 0.34 & 83 & 30 \\
\hline Pisa clay@17.0m & 0.138 & 0.027 & 0.196 & 0.083 & 0.601 & 0.011 & 0.41 & 62 & 34 \\
\hline Pisa clay@17.5 m & 0.121 & 0.027 & 0.223 & 0.074 & 0.612 & 0.010 & 0.37 & 66 & 29 \\
\hline Modena clay@14.5 m & 0.105 & $\sim 0.028$ & 0.267 & 0.071 & 0.677 & 0.011 & $\sim 0.39$ & 89 & 55 \\
\hline Modena clay@17.2m & 0.088 & $\sim 0.028$ & 0.318 & 0.060 & 0.682 & 0.013 & $\sim 0.46$ & 85 & 52 \\
\hline
\end{tabular}

from, the virgin compression line, enables not only the complete, curved, reloading branch of a load-cycle in an oedometer to be captured but also the soil response to intermediate load-unload excursions emanating from a point on a reloading line.

The formulation also provides linear ' $\log \left(m_{\mathrm{v}}\right)-\log$ $\left(p^{\prime}\right)$ ' relationships for each of the three sections of any load, unload and reload cycle, that provide realistic and practically useful guidance on $m_{\mathrm{v}}$ values; typically in the form $m_{\mathrm{v}}=C^{\prime} / p^{\prime}$.

For a particular soil, the shape of each of the family of possible reload curves, and the slope $(\theta)$ of their image line in a ' $\log \left(m_{\mathrm{v}}\right)-\log \left(p^{\prime}\right)$ ' diagram, is shown to depend solely on the 'unloading ratio' used in the oedometer test (i.e., the ratio of the $p^{\prime}$ value on the virgin $C_{\mathrm{c}}^{\prime}$ line from which unloading along a $C_{\mathrm{s}}^{\prime}$ line starts, to the $p^{\prime}$ value at which reloading begins).

Since an overconsolidation ratio $\eta$ is a specific form of unloading ratio the laboratory reload curve of a structurally undisturbed soil-sample should belong to this family. This assumption enables a rational estimate to be made of the $m_{\mathrm{v}}$ versus $p^{\prime}$ relationship when the soil is loaded insitu. For soils at $\eta$ values close to unity, subjected to a small, in-situ, unloading reloading excursion at $p_{\mathrm{i}}$ on the virgin compression line, a reasonable approximation to $m_{\mathrm{v}}$ is shown to be, $m_{\mathrm{v}}^{*}=\left(C_{\mathrm{c}}^{\prime}+C_{\mathrm{r}}^{\prime}\right) /\left(2 p_{\mathrm{i}}^{\prime}\right) \approx C_{\mathrm{c}}^{\prime} /\left(2 p_{\mathrm{i}}^{\prime}\right)$.

The main conclusion to be drawn from the modelling is that the set of $C^{\prime}$ parameters provide a very much more powerful and satisfactory means of interpreting confined compression in an oedometer than either $\left(C_{\mathrm{s}}, C_{\mathrm{c}}\right)$ or $m_{\mathrm{v}}$.

\section{REFERENCES}

1) Baligh, F. (1984): The response of raked piles in deep and shallow beds, PhD Thesis, University of Southampton, UK.

2) Butterfield, R. (1979): A natural compression law for soils (An advance on $\left.e-\log p^{\prime}\right)$, Géotechnique, 29(3), 469-480.

3) Butterfield, R. and Baligh, F. (1996): A new evaluation of loading cycles in an oedometer, Géotechnique, 46(3), 547-553.

4) Butterfield, R., Simonini, P., Gottardi, G. and Cola, S. (2003): A new interpretation of the compressibiity of Venetian silty-clay soils, BGA, Int. Conf. on Foundations 2003, University of Dundee.

5) Butterfield, R. (2004): On subsidence and eustacy in relation to Venice, Advances in Geotech. Engng. Skempton Conf., ICE, London, 2,1231-1242.

6) Cola, S. and Simonini, P. (2002): Mechanical behaviour of Silty soils in the Venice lagoon as a function of their grading characteristics, Canadian Geotechnical Journal, 39, 879-893.

7) Den Haan, E. J. (1992): The formulation of virgin compression of soils, Géotechnique, 42(3), 465-483.

8) Hashiguchi, K. (1995): On the linear relations of $v-\ln p$ and $\ln v-\ln p$ for isotropic consolidation of soils, Int. J. Num. Methods in Geomech, 19, 367-376.

9) Janbu, N. (1963): Soil compressibility as determined by oedometer and triaxial tests, Proc. Eur. Conf. Soil Mech, Wiesbaden, 1, 19-26.

10) Juarez-Badillo, E. (1965): Compressibility of soils, Proc. 5th Symp. Behaviour of Soil Under Stress, 1(A2), 1-35. Bangalore: Indian Institute of Science.

11) Lambe, T. W. and Whitman, R. V. (1969): Soil Mechanics, John Wiley.

12) McDermott, R. J. W. (1972): Deformation characteristics of sand under axi-symmetric loading, PhD Thesis, University of Manchester, UK.

13) Nash, D., Lings, M., Benhamed, N., Sukolrat, J. and Muir Wood, D. (2006): The effects of controlled destructuring on the small strain shear stiffness $G_{0}$ of Bothkennar clay, Soil Stress-Strain Behaviour, Measurement Modelling and Analysis, Geotech. Symp, Rome, 287-298.

14) Ricceri, G. and Butterfield, R. (1974): An analysis of Compressibility data from a deep borehole in Venice, Géotechnique, 24(2), $175-192$.

15) Rowe, P. W. (1975): Inherent difficulties in the application of geotechnical science, Symposium on Recent Developments in the Analysis of Soil Behaviour and Their Application to Geotechnical Strucures, Univ. NSW, Australia.

\section{APPENDIX}

\section{Mathematica Code for Processing Oedometer Data}

This Mathematica notebook uses the ' $\log v-\log p$ ' model to optimise the fit of $C^{\prime}$ compressibility parameters 
to an unload-reload loop in an oedometer test and plots the model output together with the associated ' $\log m_{\mathrm{v}}-\log$ p' diagram.

In the notebook the $C^{\prime}$ parameters are, for convenience, designated by $C$ and vertical effective stresses by $p$. The symbols used are defined in Figs. 1(a, b). The minimum input required by the code is,

1. Experimentally determined $C_{\mathrm{c}}^{\prime}$ and $C_{\mathrm{s}}^{\prime}$ values and an initial estimate of $C_{\mathrm{r}}^{\prime}$.

2. End coordinates of an unloading $C_{\mathrm{s}}^{\prime}$ line that extends from point ' $\mathrm{a}$ ' $\left(p_{\mathrm{a} 1}, v_{\mathrm{a} 1}\right)$ on the $C_{\mathrm{c}}^{\prime}$ line to $\left(p_{\mathrm{b} 1}\right)$ in an oedometer test.

3. An approximate value of $p\left(p_{\mathrm{cl}}\right)$ at which the reloading curve, from point ' $b$ ', rejoins the virgin curve at point ' $c$ '.

Consistent values of $C_{\mathrm{o}}^{\prime}$ and $p_{\mathrm{c}}$ are calculated iteratively within the code to ensure that the reload curve $(b c)$ merges with the virgin line at ' $c$ '. The iteration process simply uses the specified $C_{\mathrm{c}}^{\prime}$ and estimated $p_{\mathrm{c} 1}$ values to calculate $\alpha 1$ (using Eq. (7)), hence $v_{\mathrm{c} 1}$ (using Eq. (9)) and an improved $p_{\mathrm{c} 2}$ value (using the first of Eq. (10 with $\left(p_{\mathrm{a}}, v_{\mathrm{a}}\right)$ replacing $\left.\left(p_{\mathrm{o}}, v_{\mathrm{o}}\right)\right)$ repeating the cycle to arrive at an $\left(\alpha, p_{\mathrm{c}}\right)$ pair of values in which $p_{\mathrm{c}}$ changes by $<1 \%$ per cycle. $C_{\mathrm{o}}^{\prime}$ is then provided by Eq. (7).

It is recommended that the reloading curve output from the model (Eq. (9)) be superimposed on a plot of the oedometer test results. Following inspection of such a plot the estimate of $C_{\mathrm{r}}^{\prime}$, and thereby $C_{\mathrm{o}}^{\prime}$ also, can usually be improved, the code run again and the process repeated until fitted and actual loading loops coincide satisfactorily.

The following SEVEN quantities are the mandatory input (those used below are for the Cambridge clay, loop E1 in Fig. 4(a))

$\mathrm{pal}=.9208 ; \quad \operatorname{val}=1.852 ; \mathrm{pb} 1=.1094 ; \mathrm{pc} 1=2 ; \mathrm{Cc}=$ $.13 ; \mathrm{Cs}=.021 ; \mathrm{Cr}=.008$;

(p1, p2) define arbitrary endpoints for plotting the $\mathrm{C}^{\prime} \mathrm{c}$ line-these may be altered

$\mathrm{p} 1=\mathrm{pa} 1 / 4 ; \mathrm{p} 2=5 * \mathrm{pa} 1$;

An iteration procedure, to find $\mathrm{pc}$, alpha, and $\mathrm{C}^{\prime} \mathrm{o}$ values which ensure that the reload curve merges correctly with the $C^{\prime} c$ line at $p=p c$ in a logv-logp diagram, is:

$\mathrm{vb} 1=\mathrm{val} *(\mathrm{pa} 1 / \mathrm{pb} 1)^{\wedge} \mathrm{Cs} ;(*(\mathrm{pa} 1, \mathrm{va} 1)$ and $(\mathrm{pb} 1, \mathrm{vb} 1)$

are on a $\mathrm{C}^{\prime} \mathrm{s}$ line $*$ )

$\mathrm{pc} 2=0 ; \mathrm{pc} 3=\mathrm{pc} 1$;

iterfunc $:=(\mathrm{pc} 1=\mathrm{pc} 3 ;$ al pha $1=\log [\mathrm{Cc} / \mathrm{Cr}] / \log [\mathrm{pc} 1 /$

pb1] -1 ;

gammal $=1 /(1+$ al phal $)$;

$\mathrm{vcl}=\mathrm{vb} 1 * \operatorname{Exp}\left[\right.$ gammal $* \mathrm{Cr} *\left(1-(\mathrm{pcl} 1 / \mathrm{pb} 1)^{\wedge}(1+\right.$

alpha1)) ] ;

$\left.\mathrm{pc} 2=\mathrm{pa} 1 *(\mathrm{va} 1 / \mathrm{vc} 1)^{\wedge}(1 / \mathrm{Cc}) ; \mathrm{pc} 3=\mathrm{pc} 2 ;\right)$

While lAbs [pc2-pc1] >pc1/100, iterfunc] ; (*itera-

tion loop for alpha and $p_{\mathrm{c}}{ }^{*}$ )

Definitions of various parameters

$\mathrm{pc}=\mathrm{pc} 2 ; \mathrm{mult}=\mathrm{Cr} / \mathrm{pb}^{\wedge}(1+\mathrm{alpha} 1) ; \operatorname{gamma} 1=1 /(1$

+ alphal) ; papbratio $=$ pal $/$ pbl ;

Co $=$ mult $*\left(p^{\prime} 1^{\wedge}(1+\right.$ alphal $\left.)\right) ;(*$ this is the best-fit Co for a defined Cr value $*$ ) $\mathrm{a}=(\log [\mathrm{Co} / \mathrm{Cs}] / \log [\mathrm{CC} / \mathrm{Cs}]) ;$

eqcC $=\mathrm{N}[(-\mathrm{CC} * \mathrm{z}+\log [10, \mathrm{val}]+\mathrm{CC} * \log [10, \mathrm{pal}])] ;$ eqcs $=\mathrm{N}[(-\mathrm{Cs} * \mathrm{z}+\log [10, \mathrm{va} 1]+\mathrm{Cs} * \log [10$, pal $])] ;$ eqbc $=\mathrm{N}\left[\right.$ gamma $1 * \mathrm{Cr} * 0.4343 *\left(1-10^{\wedge}(\mathrm{z} *(1+\mathrm{a} l \mathrm{pha} 1)) /\right.$ $\left.\left.\left(\mathrm{pbl}^{\wedge}(1+\mathrm{alpha} 1)\right)\right)+\log [10, \mathrm{vb} 1]\right]$;

The following section constructs the various parts of the basic logv-logp diagram.

gcc1=Plot $[\operatorname{eqcc},\{\mathrm{z}, \log [10, \mathrm{p} 1], \log [10, \mathrm{p} 2]\}$, Displayfunction $->$ Identity, Plotstyle - $>$ Thickness[.007]]; (* plots the Cc line $*$ )

$\operatorname{gcs} 1=\operatorname{plot}[\operatorname{eqcs},\{z, \log [10, p a 1], \log [10, p b 1]\}, D i s-$ playfunction $->$ Identity, Plotstyle - $>$ Thickness[.007]]; (* plots the Cs line *)

gbc1 $=P \operatorname{lot}[$ eqbc, $\{z, \log [10, p b 1], \log [10, p c]\}$, Displayfunction $->$ Identity,Plotstyle - $>$ Thickness[.007]]; ( $*$ plots the reloading curve bc $*$ )

lnvlnpgraph $=$ Show $\{$ gccl,gcsl,gbcl $\}$,GridLines- $>$ Automatic, Frame- $>$ True, PlotLabel $->$ ' 'Log(v) versus $\log \left(\mathrm{p}^{\prime}\right)$ plot with unload reload curve"',

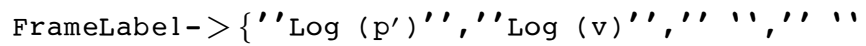
\} , DisplayFunction $->$ \$Displayfunction $]$;

Cr can be changed at this stage, if necessary, and the code re-run to improve the fit between the model output and the experimental data.

The following section simply constructs the various parts of the logmv-logp diagram using base 10 logarithms, $\mathrm{x}=$ $\log [10, p]$.

$\mathrm{g} 4=\mathrm{P} \operatorname{lot}[-\mathrm{x}+\log [10, \mathrm{Cc}]$,

$\{\mathrm{x}, \log [10, \mathrm{pb} 1], \log [10, \mathrm{p} 2]\}$, DisplayFunction $->$

Identity, Plotstyle->Thickness[.005]];

$\mathrm{g} 5=\mathrm{P} \operatorname{lot}[-\mathrm{x}+\log [10, \mathrm{Cs}],\{\mathrm{x}, \log [10, \mathrm{pb} 1], \log [10, \mathrm{p} 2]$

\}, Displayfunction - > Identity, Plotstyle->Thickness[.005]];

$g 6=P \operatorname{lot}[-x+\log [10, \operatorname{Co}],\{x, \log [10, p b 1], \log [10, p 2]$

\} , Displayfunction - > Identity, Plotstyle->Thickness [.005]];

$g 7=P \operatorname{lot}[-x+\log [10, C r],\{x, \log [10, p b 1], \log [10, p 2]$ \},Displayfunction - > Identity, Plotstyle->Thickness [.005]];

$\mathrm{g} 8=\mathrm{P} \operatorname{lot}[\log [10, \mathrm{mu} 1 \mathrm{t}]+\mathrm{a} l$ pha $1 * \mathrm{x}$,

$\{x, \log [10, p b 1], \log [10, p c]\}, P l o t S t y l e->$

$\{$ Thickness [.008], Hue [. 3], Dashing [ $\{.025, .025\}]\}$, Displayfunction - $>$ Identity $]$;

g9 $=\operatorname{ListPlot}[\{\{\log [10, \mathrm{pa} 1], \log [10, \mathrm{Cs} / \mathrm{pa} 1]\}$,

$\{\log [10, \mathrm{pa} 1], \log [10, \mathrm{Cc} / \mathrm{pa} 1]\}\}, \mathrm{PlotJoined}->$

True,Displayfunction - $>$ Identity, Plotstyle ->

Thickness[.005]]; g10=Listplot

$[\{\{\log [10, \mathrm{pb} 1], \log [10, \mathrm{Cs} / \mathrm{pb} 1]\}$,

$\{\log [10, \mathrm{pb} 1], \log [10, \mathrm{Cr} / \mathrm{pb} 1]\}\}, \mathrm{PlotJoined}->$

True, Displayfunction - $>$ Identity,

Plotstyle - > Thickness [.005]];

lnmvlnpgraph $=$ Show $\{$ g4,g5,g6,g7,g8,g9,g10 $\}$, GridLines - $>$ Automatic, Frame - $>$ True ,PlotLabel - $>$ ' 'Log (mv) versus Log $\left(p^{\prime}\right)$ plot + the $C^{\prime}$ and alpha

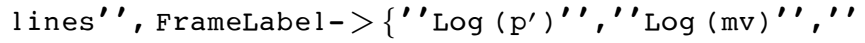
' ,' ' $\}$, DisplayFunction $->$ \$DisplayFunction $]$; 
The following outputs various parameters and other quantitites needed for calculating mv values and external plotting

nalpha $=$ NumberForm $[a l p h a 1,4]$;

nCo $=$ NumberForm $[\mathrm{Co}, 4] ; \mathrm{nvb}=$ NumberForm $[\mathrm{vb} 1,4]$;

$\mathrm{nvc}=$ NumberForm [ vc1, 4$] ; \mathrm{npc}=$ NumberForm [ pc , 4];

npapbratio = NumberForm [ papbratio, 4$]$;

prl $=$ Print [stringForm[ 'Parameters input are: C'c

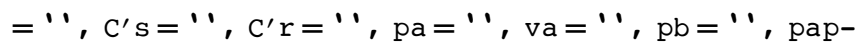
bratio="'", Cc, Cs, Cr, pal, val, pbl, npapbratio ] ] ;

pr2 = Print [StringForm[ ' Parameters output are: C'O $=$ '", al pha $=$ '",

$\mathrm{vb}={ }^{\prime}, \mathrm{pc}={ }^{\prime}, \mathrm{vc}={ }^{\prime} \cdots, \mathrm{nco}$, nalpha, nvb, npc, nvcl] ; 